\title{
The economic consequences of attention- deficit hyperactivity disorder in the Scottish prison system
}

\author{
Susan Young ${ }^{1,2^{*}}$ (D, Rafael A. González ${ }^{3}$, Moshe Fridman ${ }^{4}$, Paul Hodgkins ${ }^{5}$, Keira Kim ${ }^{6}$ and Gisli H. Gudjonsson ${ }^{2,7}$
}

\begin{abstract}
Background: Attention-deficit hyperactivity disorder (ADHD) is highly prevalent amongst prison inmates and the criminal justice system (CJS) likely bears considerable costs for offenders with ADHD. We aimed to examine the relationship between ADHD and health-related quality of life (HRQoL) and quality-adjusted life years (QALY) amongst imprisoned adults; and to estimate the annual expenditure associated with ADHD status in prison.

Methods: An observational study was performed in 2011-2013, at Porterfield Prison, Inverness, United Kingdom (UK). The all male sample included 390 adult prison inmates with capacity to consent and no history of moderate or severe intellectual disability. Participants were interviewed using the Diagnostic Interview for ADHD in Adults 2.0. The Health Utilities Index Mark 3 (HUI3) was used to measure health status, and to calculate attribute specific HRQOL scores and QALY. Health service utilisation was obtained through inspection of medical prison records. Inmates with ADHD were compared with inmates without ADHD.

Results: Inmates with ADHD had significantly lower QALYS, with a clinically significant adjusted difference of 0.13. Psychiatric co-morbidity accounted for the variation of ADHD on the HUI3 emotion domain only. Medical costs for inmates with ADHD were significantly higher; and behaviour-related prison costs were similar to prisoners without $A D H D$, reflecting a low frequency of recorded critical incidents.

Conclusions: ADHD may directly contribute to adverse health and quality of life through cognitive and executive function deficits, and co-morbid disorders. The extrapolation of conservative cost estimates suggests that the financial burden of medical and behavior-related prison care for inmates with ADHD in the UK is approximately $£ 11.7$ million annually. The reported cost estimates are conservative as there is great variability in recorded critical incidents in prisons. In turn, for some prison establishments the prison care costs associated with prisoners with ADHD may be considerably greater.
\end{abstract}

Keywords: ADHD, Health-related quality of life, Economic evaluation, Quality-adjusted life years, Prison, Costs

\section{Background}

Among the general population attention-deficit hyperactivity disorder (ADHD) confers significant financial burden $[1,2]$ and given the disproportionate prevalence in the prison population, the criminal justice system (CJS) likely bears considerable economic consequences for offenders with ADHD.

\footnotetext{
* Correspondence: suzyyoung@aol.com

${ }^{1}$ Psychology Services Limited, PO Box 1735, Croydon CR97AE, UK

${ }^{2}$ Reykjavik University, Reykjavik, Iceland

Full list of author information is available at the end of the article
}

ADHD is a childhood onset neurodevelopmental disorder [3] often persisting into adulthood. It is one of the most common mental health disorders in children with recent prevalence estimates ranging between 5.9 and $7.1 \%[4,5]$. There is recent evidence suggesting late-onset of ADHD, which will require research to better understand its implication [6, 7]. Clinically significant symptoms persist beyond childhood in $65 \%$ of cases [8], and may affect as much as $2.8-5.3 \%$ of adults worldwide $[9,10]$. Its substantial burden of disease is evidenced by an increased likelihood for serious accidents [11], earlier mortality rates [12], substance dependence [13],

(c) The Author(s). 2018 Open Access This article is distributed under the terms of the Creative Commons Attribution 4.0 International License (http://creativecommons.org/licenses/by/4.0/), which permits unrestricted use, distribution, and reproduction in any medium, provided you give appropriate credit to the original author(s) and the source, provide a link to the Creative Commons license, and indicate if changes were made. The Creative Commons Public Domain Dedication waiver (http://creativecommons.org/publicdomain/zero/1.0/) applies to the data made available in this article, unless otherwise stated. 
criminality, incarceration, and false confessions [14]. ADHD confers significant impairment [15], and reduced quality of life [16] to those afflicted by it. It is also highly prevalent amongst prison inmates, with a meta-analytical prevalence estimate of 25.5\% [17]. Prison inmates with ADHD are reported to be at significant risk for having increased psychiatric co-morbidity and poorer psychosocial adjustment to the prison environment [18-21].

Health economic evaluations have become an essential part of research and provide evidence supporting health interventions [22]. ADHD is consistently linked with substantially elevated costs and with significant economic burden on education [23] and health [2]. Annual service costs linked with ADHD are reportedly $£ 670$ million in the UK [24]. Meanwhile, annual ADHD-related healthcare costs are estimated between $\$ 21$ to $\$ 44$ billion in the United States [23]. Furthermore, in the US costs associated with accident claims are more than three times higher in adults with ADHD [1].

Despite the disproportionate representation of ADHD within the prison population, the health-related quality of life (HRQoL) and related costs remains unknown.

In this study we aim to examine the impact of ADHD amongst imprisoned adults. We set out to determine prisoners': 1) scope and extent of impaired HRQoL utility scores and quality-adjusted life years (QALY) and 2) service use and costs attributable to ADHD.

\section{Methods}

\section{Participants and sample selection}

Following approval from the Scottish Prison Service Research Access and Ethics Committee and in accordance with the Declaration of Helsinki written consent was obtained by prisoners who were recruited by opportunity sampling from Porterfield Prison, Inverness, Scotland, UK, over a period of 18 months in 2011-2013. Participants included 390 adult male prisoners who consented to participate. Those with moderate or severe learning difficulties, lack of fluency in the English language, and severe mental illness (as judged by prison officers) were excluded from participating.

Participants in the study were indirectly compensated. The study group deposited $£ 20$ per participant into a Prison Common Good Fund, which was managed by a group of prisoners. The fund was then used to purchase items for the common good of all prisoners to enhance prison life.

Prisoners who indicated interest attended an appointment with the researcher where they were given detailed oral and written information about the study and the consent procedures. After obtaining written consent, researchers administered a comprehensive battery of measures, which took approximately $4 \mathrm{~h}$ to complete (usually split across 2 or 3 sessions). The researchers received comprehensive training to administer the measures from the Maudsley Hospital Adult ADHD Service. Further details about the comprehensive battery of measures have been published elsewhere [25].

Data related to medical service use were gathered through inspection of prison medical records and medical costs were calculated based on reference costs reported by the (NHS; see details below). Data related to behavioural disturbance incidents were gathered through inspection of prison records and related costs were calculated based on similar reference costs and were reported as prison costs (see details below).

\section{Measures}

Health utilities index mark 3 (HUI3)

The HUI3 is a multi-attribute health status classification system that enables researchers to map levels in the following categories: vision, hearing, speech, ambulation, dexterity, emotion, cognition, and pain; using decision tables and coding algorithms, which can be represented in terms of attribute specific HRQoL scores [26, 27]. HRQoL refers to the value assigned to life span when considering impairments and functional states that may be affected by disease, injury, and treatment [28]. The HUI3 scoring system provides HRQoL utility scores ranging from 0.00 (dead) to 1.00 (perfect health), and meets criteria for calculating QALY [26]. Prisoners' were asked to answer HUI3 questions based upon their health status in the 4 weeks prior to the interview. The HUI3 composite score was used to calculate QALY and was extrapolated to 1 year to represent the study health evaluation time frame, as previously applied on cost-effectiveness studies [29]. Estimating beyond this time frame would have introduced a very high degree of uncertainty in estimates.

\section{ADHD diagnosis}

All participants underwent a comprehensive evaluation for ADHD and were interviewed using the Diagnostic Interview for ADHD in Adults 2.0 (DIVA-2) [30]. The DIVA-2 is a validated semi-structured clinical interview used to diagnose ADHD in adults based on the 5th edition of Diagnostic and Statistical Manual of Mental Disorders (DSM-5) criteria [3]; and has been used in clinical [31] and law enforcement settings [32]. Questions addressed their current and childhood (ages 5 to 12) presentation of ADHD symptoms and scope of impairment.

Participants were also questioned whether they were previously diagnosed or treated for ADHD or any other psychiatric illness. 


\section{Brief symptom inventory (BSI)}

The Brief Symptom Inventory (BSI) is a brief psychological self-report scale [33]. The BSI has 9 subscales (Somatization, Obsession-compulsion, Interpersonal sensitivity, Depression, Anxiety, Hostility, Phobic anxiety, Paranoid ideation and Psychoticism), and 3 composite measures (Global Severity Index, Positive Symptom Distress Index, and Positive Symptom Total). We used the BSI depression and anxiety measures as covariates in our health evaluation models because they represent common mental health conditions.

\section{Medical service use and costs}

Detailed medical service utilization history was obtained through inspection of participants prison medical records. Data from prisoners' medical charts (covering the 3 months prior to the appointment with the researcher) were abstracted, verified, and entered into a database for analyses. The authors chose to include 3 months of service for practical reasons; and additionally thought this time period fairly represented the medical service use of all prisoners given the variance in prison stays. Data included details from appointments with a general practitioner, physical health nurse, mental health nurse, addiction services nurses, or any other type of nurse, psychiatrist, psychologist, podiatrist, oral health practictioner, or any other type of health related visit such as Well-man clinic or other health clinics, and hospital outpatient visit. Medical costs for these appointments were calculated according to reference costs reported by the NHS Trust [34]. Medication costs were not explicitly collected in the study.

\section{Prison service use and costs}

Prisoners' behavioural disturbance incidents were obtained from prison records. Reports of non-attendance to prison activities, being under observation, number of adjudications, and critical incidents were collected and used to calculate the related prison costs. Prison costs were calculated based upon reference costs from the UK Ministry of Justice and HM Prison Service [35], Social Research Unit, Dartington [36], and from direct communication with Scottish Prison Service management.

All reported costs were in Pounds Sterling $(£)$ for the years 2012-2015, and adjusted using the Consumer Price Index (CPI, 2016).

\section{Analytical strategy}

Frequencies were reported for all categorical variables, and means with their standard deviation for continuous variables. The median and inter-quartile range was used for all cost related values.

Because of the HUI3 utility scores' interval properties, we used t-tests for unadjusted analyses. To estimate the association between ADHD and HUI3 single attribute and composite utility scores, Type I Tobit models were used in favour of traditional ordered logistic regression models. A Tobit model is designed to estimate linear relationships between variables when there are ceiling or flooring effects on the outcome [37]. Ignoring the censoring and fitting regression models estimated using OLS would have been systematically biased toward the null hypothesis, whereby type II error is increased. HUI3 single attribute and composite utility scores with the value of one are considered censored.

Considering the highly skewed nature of cost variables we used generalised linear models (GLM) with a gamma distribution and log-link function. This way the natural $\log$ is modeled and then the predicted margins are calculated in order to obtain the cost differential for those with ADHD [38]. All cost models were adjusted only for age. HUI3 includes an emotion domain that may be sensitive to coexisting disorders (in addition to ADHD). Therefore, models for all HUI3 variables were further adjusted for co-morbid anxiety and depression standardized symptom scores.

We established a significance level at $p \leq 0.05$ for all statistical tests. All analyses were performed using Stata version 13 (StataCorp) [39].

\section{Results \\ Descriptive statistics}

The all male sample was essentially Caucasian British (99.0\%) with an average age of 30.3 years (sd 8.3). Prisoners with ADHD had a significantly lower mean age than those without ADHD (28.2 years (sd 7.5) vs. 31.0 years (sd 8.5,) $p<0.01$ ). 18.8\% (18/96) prisoners with ADHD reported a prior diagnosis of ADHD and $15.6 \%(15 / 96)$ reported having ever received pharmacological treatment for ADHD.

Out of the total sample of 390 participants, 81 (20.8\%) required assistance with reading the questionnaires. For those diagnosed with ADHD, 31/96 (32.3\%) required assistance in contrast to 50/294 (17.0\%) of the other participants. This difference is significant $\left(\mathrm{Chi}^{2}(d f 1)=10.2\right.$, $p=0.001$; Odds Ratio $=2.3$, Confidence Interval 1.3-3.9).

\section{Health status}

Table 1 includes the mean and distribution of all HUI3 specific attributes and composite HRQoL utility scores for all inmates. Prisoners' variability noticeably increased in scores for emotion, cognition, pain, and HRQoL.

Independent sample t-tests were estimated for all utility scores and HRQoL (Table 2) comparing prisoners with ADHD with prisoners without ADHD. Inmates with ADHD had significantly lower scores in the following categories: speech $(p<0.05)$, ambulation $(p<0.01)$, emotion $(p<0.001)$, cognition $(p<0.001)$, pain $(p<0.05)$, 
Table 1 Distribution of HUI3 Specific Attribute Utility Scores for all Inmates

\begin{tabular}{llll}
\hline HUI3 Attributes, $N=390$ & $\mathrm{n}$ & Mean score & Standard deviation \\
\hline Vision & 385 & 0.989 & $(0.024)$ \\
Hearing & 387 & 0.989 & $(0.061)$ \\
Speech & 390 & 0.966 & $(0.073)$ \\
Ambulation & 389 & 0.991 & $(0.072)$ \\
Dexterity & 390 & 0.985 & $(0.078)$ \\
Emotion & 370 & 0.787 & $(0.274)$ \\
Cognition & 390 & 0.837 & $(0.237)$ \\
Pain & 390 & 0.854 & $(0.278)$ \\
HRQoL & 362 & 0.647 & $(0.307)$ \\
\hline
\end{tabular}

Notes: HUI3 data covered the 4 weeks prior to interview

Cost per unit is defined as cost per inmate for each visit. Median medical costs were calculated from data collected from medical records covering the 3 months prior to interview

ancludes Hepatitis C, Harm reduction, and Smoking cessation nursing staff

${ }^{b}$ Includes any other recorded health visits, e.g. Well-man clinic

Includes all missed prison therapeutic and other activities per inmate

${ }^{d}$ Calculated by time spent and number of prison staff involved (based on average hourly pay rate)

${ }^{e}$ Calculated by time spent and number of prison staff involved in any adjudication process (estimated $15 \mathrm{~min}$. Per process)

and HRQoL composite $(p<0.001)$. Figure 1 shows the distribution of HRQoL utility scores comparing prisoners without ADHD with those with ADHD.

Table 3 demonstrates that even after adjustment for age, anxiety, depression, and/or without correction for missing values, that censored Tobit models were significant in each adjusted model for vision, ambulation, emotion, cognition, and QALY. The inclusion of anxiety and depressive disorders in models 2 and 3, attenuated the associations with emotion, hearing, and pain attributes. Attenuation of the association with hearing and pain should be interpreted with caution, as their unadjusted effect sizes were small. Models 2 and 3 show that prisoners with ADHD have a significant difference in QALY of 0.13 and 0.10 , compared to those without ADHD.
$25 \%$ of all participants had missing values by endorsing 'Don't Know' on several questions of the HUI3. Patterns of missing values were analysed and the most plausible values were imputed using a technique developed by Naeim and colleagues specifically for HUI-3 scores [40].

All 41 questions of the HUI-3 instrument allow respondents to answer 'Don't Know'. Because there are no instructions in the instrument manual for how to manage or score these answers, the 'Don't Know' category interferes with the scoring leading to substantial amounts of missing data. Common methods for imputing data in this scenario may not be as effective or can even be misleading, given that answers to other questions within the same domain (e.g. vision) often help identify a sole correct answer to those marked as 'Don't Know'. The well cited imputation method by Naeim et al. [40] advises inspecting each possible change in attribute score for every answer to the 'Don't Know' missing value, then selecting the most plausible value accordingly.

Furthermore, we performed a sensitivity analysis based only on those with complete HUI3 data to examine any differences in estimates before and after using the inspection and deduction method to account for 'Don't Know' answers.

\section{Service utilization and costs}

Table 4 includes all cost model inputs for the total median associated medical and prison costs for all inmates.

Table 5 shows that in terms of medical service utilisation, prisoners with ADHD visited significantly more general practitioners $(p<0.05)$, physical health nurses $(p$ $<0.05)$, and mental health nurses $(p<0.01)$ in the three-month period assessed. No significant associations were observed for any other health services.

Table 6 shows that age adjusted medical costs were significantly greater among inmates with ADHD $(p<$ 0.05), but prison costs were not. Cost items were assessed based on a 3 month window, then calculated

Table 2 HUI3 Attribute Utility Scores by ADHD Group ( $n=96$ ADHD, $n=294$ non-ADHD)

\begin{tabular}{|c|c|c|c|c|c|}
\hline HUI3 Attributes & $\begin{array}{l}\text { No ADHD } \\
\text { Mean score }\end{array}$ & $\begin{array}{l}\text { ADHD } \\
\text { Mean score }\end{array}$ & $t$ & Effect size $(d)$ & $p$ \\
\hline Vision & 0.991 & 0.986 & 1.839 & 0.218 & 0.067 \\
\hline Hearing & 0.992 & 0.979 & 1.938 & 0.229 & 0.053 \\
\hline Speech & 0.971 & 0.952 & 2.20 & 0.259 & 0.028 \\
\hline Ambulation & 0.997 & 0.974 & 2.71 & 0.319 & 0.007 \\
\hline Dexterity & 0.984 & 0.986 & -0.113 & -0.013 & 0.910 \\
\hline Emotion & 0.817 & 0.692 & 3.83 & 0.466 & $<0.001$ \\
\hline Cognition & 0.879 & 0.709 & 6.41 & 0.753 & $<0.001$ \\
\hline Pain & 0.874 & 0.792 & 2.52 & 0.296 & 0.012 \\
\hline HUI3 Composite HRQoL & 0.699 & 0.477 & 6.15 & 0.759 & $<0.001$ \\
\hline
\end{tabular}




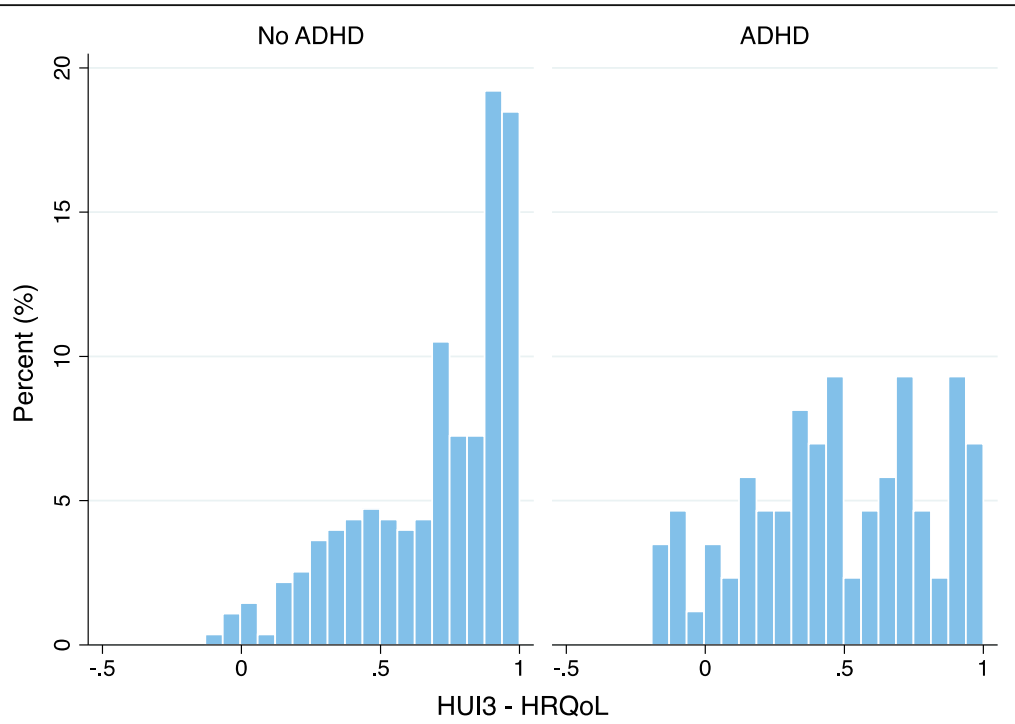

Fig. 1 Distribution of HUI3 Composite HRQoL scores by ADHD group: A greater proportion of inmates without ADHD have HUI composite HRQoL scores above 0.7. There is a greater amount of variability in the HUI composite HRQoL scores among inmates with ADHD

for 1 year assuming similar patterns of health service utilisation and behaviour in prison. Total medical and prison costs for inmates with ADHD were $£ 590$ more per year than for inmates without ADHD.

\section{Discussion}

\section{HUI3 health attributes and QALY}

To the best of our knowledge, our study is the first addressing ADHD health status using HUI3 amongst prison inmates. Previous studies documented the relationship between symptom severity and poorer HRQoL, including somatic symptoms [41], whereas a UK cross-sectional study reported that across most health domains, children and adolescents with ADHD had poorer scores when compared with samples of children with diabetes, and a healthy comparison group [42]. These studies highlight the extent that ADHD has on the health impact on affected individuals.

We analysed the role of ADHD on QALY based on a one-year horizon. Notably, the proportion of inmates with a HRQoL over 0.90 (healthy state) was vastly superior amongst those without ADHD. The final adjusted

Table 3 Adjusted Regression Models for HUI3 Attribute Utility Scores for Inmates with ADHD Compared with Inmates without $\operatorname{ADHD} ;(n=96$ ADHD, $n=294$ non-ADHD)

\begin{tabular}{llll}
\hline & Model 1 & Model 2 & Model 3 \\
\hline HUI3 attributes & Beta coef. (se) & Beta coef. (se) & $-0.04(0.01)^{* *}$ \\
Vision & $-0.04(0.01)^{* *}$ & $-0.04(0.01)^{* *}$ & - \\
Hearing & $-0.48(0.22)^{*}$ & $-0.30(0.20)$ & $-0.05(0.05)$ \\
Speech & $-0.08(0.04)$ & $-0.05(0.05)$ & $-0.54(0.25)^{*}$ \\
Ambulation & $-0.51(0.23)^{*}$ & $-0.54(0.25)^{*}$ & $-0.03(0.12)$ \\
Dexterity & $-0.06(0.11)$ & $-0.03(0.12)$ & $-0.06(0.04)$ \\
Emotion & $-0.19(0.04)^{* * *}$ & $-0.05(0.04)$ & $-0.20(0.05)^{* * *}$ \\
Cognition & $-0.29(0.05)^{* * *}$ & $-0.20(0.05)^{* *}$ & $-0.02(0.07)$ \\
Pain & $-0.15(0.07)^{*}$ & $-0.02(0.07)$ & $-0.10(0.04)^{*}$ \\
QALY derived by HUI3 & $-0.25(0.04)^{* * *}$ & $-0.13(0.04)^{* * *}$ & \\
\hline
\end{tabular}

Note. The first two columns refer to Tobit models using data that was corrected for 'don't know' answers. The third column includes the sensitivity analysis, in which we fitted a similar Tobit model but using only available data without accounting for 'don't know' answers

${ }^{a}$ All tobit models to account for censoring at the upper level of the outcome QALY

Model 1 is adjusted for age

Model 2 is adjusted for age + BSI anxiety + BSI depression

Model 3 is adjusted for age + BSI anxiety + BSI depression and is a sensitivity analysis of the sample without correction for 'don't know' answers

${ }^{*} p<0.05$

$*^{* *} p<0.01$

${ }^{* * *} p<0.001$ 
Table 4 Three-month Medical and Prison Costs for All 390 Inmates

\begin{tabular}{|c|c|c|c|}
\hline & $\operatorname{Cost}(£) /$ unit & Median cost over 3 months ( $£$ ) & Inter-quartile range $(£)$ \\
\hline \multicolumn{4}{|l|}{ Medical costs per inmate } \\
\hline General practitioner & 121 & 242 & 242 \\
\hline Physical health nurse & 74.3 & 74.3 & 74.3 \\
\hline Mental health nurse & 78.5 & 78.5 & 78.5 \\
\hline Addiction nurse & 78.5 & 78.5 & 78.5 \\
\hline Nursing other ${ }^{a}$ & 74.3 & 0 & 0 \\
\hline Psychiatrist & 148.6 & 0 & 0 \\
\hline Psychologist & 142.2 & 0 & 0 \\
\hline Podiatrist & 34 & 0 & 0 \\
\hline Oral health & 87 & 0 & 0 \\
\hline Other health visit ${ }^{\mathrm{b}}$ & 87 & 0 & 0 \\
\hline Hospital outpatient & 125 & 0 & 0 \\
\hline \multicolumn{4}{|l|}{ Prison costs per inmate } \\
\hline Activities non-attendance ${ }^{c}$ & 38.2 & 0 & 76.4 \\
\hline Observation level $^{d}$ & 13.3 & 0 & 0 \\
\hline Adjudications $^{\mathrm{e}}$ & 21.4 & 0 & 0 \\
\hline Critical incidents $^{\mathrm{d}}$ & 13.3 & 0 & 0 \\
\hline Overall medical costs & - & 464.9 & 488.3 \\
\hline Overall prison costs & - & 34.7 & 76.4 \\
\hline Overall medical and prison costs & - & 503.1 & 532.6 \\
\hline
\end{tabular}

Notes: Cost per unit is defined as cost per inmate for each visit. Median medical costs were calculated from data collected from medical records covering the 3 months prior to interview

ancludes Hepatitis C, Harm reduction, and Smoking cessation nursing staff

Includes any other recorded health visits, e.g. Well-man clinic

Includes all missed prison therapeutic and other activities per inmate

${ }^{d}$ Calculated by time spent and number of prison staff involved (based on average hourly pay rate)

${ }^{e}$ Calculated by time spent and number of prison staff involved in any adjudication process (estimated 15 min. Per process)

model that accounted for psychiatric co-morbidity produced a 0.13 difference in QALY, four-fold above the 0.03 clinically relevant threshold estimated by the instrument developers [26]. QALY based on inmates' one-year health utility scores for those with ADHD were significantly lower than those without ADHD. Poorer specific health attribute scores on vision and mobility indicate that inmates with ADHD have significantly compromised health states that go beyond of those more usually expected (such as emotion and cognition) from the disorder. Furthermore, health utilities models adjusted for psychiatric co-morbidity accounted for the variation of ADHD on emotion aspects, but not on the cognition attribute, providing an important insight regarding the contributing factors to impairment amongst inmates with ADHD.

The significantly poorer vision score among the ADHD group may relate to their reading difficulties. In the present study, those diagnosed with ADHD were over two times more likely to require assistance with reading the questionnaires than the other participants. With respect to mobility, the finding that prisoners with
ADHD have significantly poorer ambulation problems may reflect that prisoners with ADHD suffer more injuries that hinder their mobility compared with non-ADHD prisoners. Data obtained from the Danish registry reported that the morbidity rate is nearly three times higher if you have ADHD, and that $77.7 \%$ of unnatural deaths were accounted for by accidental injury [12]. Additionally, given the higher rates of aggression and violence in the ADHD population [43], there may be mobility problems arising from assault.

ADHD is frequently reported to be associated with a substantial reduction in the quality of life of children [44] and with increased chronic health problems in adults [45]. Study results indicate that ADHD impacts HRQoL with severe effects in emotional and social domains, and at least moderate effects in physical domains [46, 47]. Adult inmates in our sample had an unadjusted HRQoL of less than 0.60. It is likely that undiagnosed and untreated ADHD has a cumulative effect and increases the risk for further health impairments, especially among imprisoned adults with coexisting mental health and social problems. 
Table 5 Three-month Medical Service Utilisation for Inmates with ADHD (Compared with Inmates without ADHD; $n=96$ ADHD, $n=294$ non-ADHD)

\begin{tabular}{|c|c|c|c|}
\hline Medical service use & beta coefficient (se) & IRR $(95 \% \mathrm{Cl})$ & $p$ \\
\hline General practitioner & $0.19(0.09)$ & $1.21(1.00,1.45)$ & 0.04 \\
\hline Physical health nurse & $0.22(0.10)$ & $1.25(1.03,1.50)$ & 0.02 \\
\hline Mental health nurse $\mathrm{a}^{\mathrm{a}}$ & $0.61(0.22)$ & $1.84(1.19,2.85)$ & 0.01 \\
\hline Addiction nurse & $-0.11(0.21)$ & $0.90(0.59,1.35)$ & 0.60 \\
\hline Other nurse ${ }^{b}$ & $-0.18(0.54)$ & $0.83(0.29,2.40)$ & 0.74 \\
\hline Psychiatrist and Psychologist & $-0.12(0.80)$ & $0.89(0.19,4.27)$ & 0.89 \\
\hline Oral health & $0.93(1.46)$ & $2.54(0.14,44.74)$ & 0.53 \\
\hline Other health related visit ${ }^{c}$ & $-1.85(0.99)$ & $0.16(0.02,1.09)$ & 0.06 \\
\hline Hospital outpatient & $0.56(0.54)$ & $1.76(0.61,5.04)$ & 0.30 \\
\hline
\end{tabular}

Note: Visits to Podiatrist excluded for $n<10$

ancludes general mental health and psychiatric nursing staff

bIncludes Hepatitis C, Harm reduction, and Smoking cessation nursing staff

'Includes any other recorded health visits, e.g. Well-man clinic

There is evidence to suggest that poor HRQoL in individuals with ADHD may be driven by the existence of co-morbid conditions [48]. In our study, although co-morbidity played a role in the impact of ADHD on HRQoL, the association is not entirely explained by coexisting psychiatric symptoms of anxiety and depression. Moreover, there was no attenuation on the association with the cognitive attribute of the HUI3 on adjusted models, suggesting a domain-specific link. Cognitive dysfunction in the form of difficulties allocating attentional resources [49], response inhibition, and management of reward are hallmarks of the ADHD phenotypic expression. These results denote different paths through which ADHD may impact adverse health and quality of life, directly through cognitive deficits and via co-morbid disorders. We therefore provide evidence of domain-specific and shared contributions to impaired HRQoL in ADHD.

\section{Service use and costs}

Health economic studies on the general population report that ADHD (including symptoms of hyperactivity) is associated with significant economic burden $[1,2]$; however, studies focusing exclusively on the economic impact of ADHD on adult prisoners were not identified.
A US study of disability claims reported that patients with ADHD had 2.6 more medical claims than those without ADHD and that ADHD imposed a significant financial burden [1]. A recent prospective UK study reported that preschoolers with high levels of hyperactivity had a 17-fold increase in overall costs compared with non-hyperactive controls; costs were mainly driven by mental health, educational, social, and criminal justice system service use [2]. A Danish study reported that the direct medical costs of ADHD patients were relatively high, whereof mental care and inpatient hospitalizations accounted for approximately $60 \%$ of the costs and medication use accounted for 13\% [50]. Results of one study demonstrated that public costs (due to mental health, school services, and the juvenile justice system) are more than double for youth with ADHD compared with those without ADHD [51].

Hospital inpatient stays are a significant driver of costs attributable to ADHD. A retrospective analysis during a 9 year period reported that median hospital inpatient, hospital outpatient, or ED admission costs for individuals with ADHD were more than double for those without ADHD [52]. Pharmacotherapy costs are also a large part of medical costs attributable to ADHD. Medication costs were reported to account for about 13-38\% of total costs $[1,2,24,50,52,53]$. Psychological therapy

Table 6 Average Costs Model Results and Estimated Marginal Predictions for Inmates with ADHD (Compared with Inmates without $\mathrm{ADHD} ; n=96 \mathrm{ADHD}, n=294$ non-ADHD)

\begin{tabular}{llll}
\hline & 3 month beta coefficient & 3 month Predicted margin & 1 year Predicted margin \\
\hline Medical Costs & $0.25^{*}$ & $£ 135.9$ & $£ 543.6$ \\
Prison Costs & 0.25 & $£ 11.4$ & $£ 45.6$ \\
Total Costs & $0.24^{* *}$ & $£ 147.5$ & $£ 590$ \\
\hline
\end{tabular}

Note: Findings from Generalised Linear Model using gamma error distribution and log link function, adjusted for age 
(individual or group modalities) is often another common important driver of costs, which was essentially not utilised by the participants of our study.

Our total estimated annual cost of $£ 590$ per inmate with ADHD demonstrates that the costs attributable to ADHD are relatively high. But because our estimate did not include costs for hospital stays, medication, and/or psychological treatment, the total cost estimate therefore represents a conservative figure.

In our study, costs associated with ADHD were driven by increased medical service use and not by behavioural disturbance incidents. This may indicate that costs related to behavioural incidents were more generally distributed across the prison sample and due to many other factors besides having a diagnosis of ADHD. Service utilisation patterns were restricted to general medical and nursing services. Low endorsement of engagement with these and other services may have been a true reflection of the patterns of use in our sample, or of the Scottish prison system at large. As many resources were not used, costs remained lower compared with other studies mentioned.

Because the present study found there were significantly greater medical costs but not behaviour-related prison costs, the cost implication seems to be largely for the NHS. While the assignment of prisoner medical costs based on NHS reimbursements may not perfectly represent prisoners medical costs (possibly over- or under-estimated), it helped to estimate and interpret costs using standard more widely used and familiar terms. There may be, however, variability in the recording of critical incident data, which will be a fundamental driver of prison costs, leading to increased number of seclusions, adjudications, injury costs and potentially staff sickness. In a previous study conducted in a large prison in Aberdeen there were highly significant differences found in aggressive critical incidents between an ADHD and a non-ADHD group [43]. Hence for some prison establishments, costs to the prison service may be considerably higher.

\section{Limitations}

A key strength of the study is its large sample size and a methodology in which every participant was clinically diagnosed using the DIVA-2. Nonetheless, there are several limitations.

Because of missing data, some bias may be present in our analyses of HUI3 specific attribute scores. However, our models accounted for missing data using a well established and oft cited method and the sensitivity analysis on adjusted models allowed us to have confidence in our methods.

Ethnic minority groups and females did not have representation in this sample, therefore, it remains unclear whether these findings may be fully applicable and generalized to the entire prison population.

ADHD diagnosis was based on self-reported information and we did not include informant (e.g. familial) reports. Recall bias is unaccounted for and may have been a factor in symptom measures and service use. Nevertheless, any bias related to under-reporting was presumed to have similar effects on estimates for both the ADHD and non-ADHD groups. Other studies have reported considerably higher rates of critical incidents $[43,54]$, and it is likely that prison costs based on these would be considerably inflated compared with the estimates derived from the present data.

Our extrapolation method (using 3 months of data to estimate 1 year) may be limited in its accuracy. We used a one-year horizon for our HRQoL and service use estimates, and more time than this would have conferred too much uncertainty. Future research should address measuring utilities over more time, thereby providing a better foundation of QALY estimates beyond 1 year. Finally, the opportunity sampling method used may have introduced selection bias into the results, limiting their generalizability both within the prison and across other prisons.

\section{Conclusions}

Research on HRQoL and costs related to adult ADHD is limited in the general population and is virtually non-existent in the prison population. We addressed this paucity of data on HRQoL, QALY, service utilization, and costs attributable to ADHD based on 1 year in prison. We performed HRQoL and cost analyses for adult prison inmates with ADHD based on a cross-section of the Scottish prison system in the UK.

Our study provides evidence that HRQoL of life is considerably poorer in adult male prison inmates with ADHD, with an adjusted reduction of 0.13 QALY. Affected health attributes extend beyond emotional and cognitive deficits, suggesting chronic effects of ADHD on health over the lifespan. ADHD may contribute to adverse health and quality of life directly through executive function and cognitive deficits; and co-morbid disorders. Combined costs within prison were significantly higher for those with ADHD and were driven by medical expenses. Service utilisation was for the most part limited to general practitioner services and nursing staff visits.

Approximately $80 \%$ of inmates considered to have ADHD did not receive a prior diagnosis - indicating that a significant proportion of adult prison inmates are inadequately identified and treated. This has policy implications for both the National Health and the prison service. There is a need for the prison service to develop improved awareness about ADHD in adult prisoners, 
including the clinical and behavoural presentation of ADHD. There is also a need to introduce a brief and reliable screen on admission, such as the 6-item B-BAARS, which has high sensitivity and specificity [25]. Furthermore, there is a need for the NHS to address the general absence of health service provision for adults with ADHD in prisons, as prisoners continue presenting multiple times for their health problems and seem to remain mis- or undiagnosed.

In 2015 the Ministry of Justice reported a population of 77,472 adult male inmates in the UK. Given the prevalence rate of $25.5 \%$ of ADHD among prisoners [55] and our estimated annual total cost per adult inmate with ADHD of $£ 590$, we estimate a total cost for medical and behaviour-related prison care of approximately $£ 11.7$ million per year. This cost estimate, however, is conservative as it is seemingly driven by general medical expenses and not by critical incidents. There may be variability in the reporting of critical incidents in prisons, and prison care costs associated with behavioural disturbances may be much higher in other establishments.

ADHD is a prevalent mental health disorder, and a known risk factor for a series of adverse health and social outcomes. Population studies report the community (and society at large) bears considerable medical costs associated with ADHD [22, 23]. Although ADHD is disproportionately prevalent in prison, it is understudied and inadequately addressed in this context $[55,56]$.

Our results provide evidence that adult prisoners with ADHD represent a unique population with unmet needs and high costs. Given the Swedish study of patients showing a $32 \%$ reduction in criminality for men and $41 \%$ for women during periods when they were receiving ADHD medication [57], effective identification and treatment of ADHD may have important cost implications.

We recommend directing efforts to increase access to effective interventions for adult inmates with ADHD. Setting up provisions for better access to early diagnosis and treatment is likely to improve inmates' HRQoL and decrease impairment related to ADHD symptoms and associated co-morbidities.

\section{Abbreviations}

ADHD: Attention-deficit hyperactivity disorder; BSI: Brief Symptom Inventory; CJS: Criminal justice system; CPI: Consumer price index; DIVA-2: Diagnostic interview for ADHD in adults 2.0; DSM-5: 5th edition of Diagnostic and Statistical Manual of Mental Disorders; GLM: Generalised linear models; HRQOL: Health-related quality of life; HUI3: Health Utilities Index Mark 3; NHS: National Health Service; QALY: Quality-adjusted life years

\section{Acknowledgements}

We are grateful to Mr. Gordon Morrice, the Scottish Prison Service, and staff at Porterfield Prison in Inverness for their support of the study. We thank Laura Mutch and Isabella Mallet-Lambert for data collection. This study was supported by a grant from Shire Pharmaceutical Development Limited.

\section{Funding}

The study was supported by Shire Pharmaceutical Development Limited through a restricted grant. Shire had no role in the design and conduct of the study (collection, management, analysis, and interpretation of the data) or on the preparation, review, or approval of the manuscript, and the decision to submit the manuscript for publication. The research was also supported by the National Institute for Health Research (NIHR) Imperial Biomedical Research Centre.

\section{Availability of data and materials}

The datasets used and analysed during this current study are available from the corresponding author upon reasonable request.

\section{Authors' contributions}

SY, RG, MF, and GG led the planning and scientific input of the study. RG conducted the statistical analysis and wrote the first draft with input from SY and GG. KK critically edited the data tables, figures, and manuscript; and wrote the final draft. All authors have read and approved the final manuscript.

\section{Ethics approval and consent to participate}

Research was performed in accordance with the Declaration of Helsinki and was approved by the Scottish Prison Service Research Access and Ethics Committee (reference: 7/13/10/10). Written consent to participate was received from each prisoner.

\section{Consent for publication}

Not applicable

\section{Competing interests}

SY has received honoraria for consultancy, travel, educational talks and/or research from Janssen, Eli Lilly, HB Pharma, and/or Shire. MF consulted for Amgen, CSL Behring, Merck, Novo Nordisk, Shire, and Vertex. GG and RG have no conflicts of interest. PH was an employee of Shire working on ADHD projects from 2009 to 2013. The views expressed are those of the authors and not necessarily those of the NHS, the NIHR or the Department of Health. Aside from KK, none of the authors received funds for their involvement in this manuscript.

\section{Publisher's Note}

Springer Nature remains neutral with regard to jurisdictional claims in published maps and institutional affiliations.

\section{Author details}

${ }^{1}$ Psychology Services Limited, PO Box 1735, Croydon CR97AE, UK. ${ }^{2}$ Reykjavik University, Reykjavik, Iceland. ${ }^{3}$ East London NHS Foundation Trust, London, UK. ${ }^{4}$ AMF Consulting Inc, Los Angeles, CA, USA. ${ }^{5}$ Sage Therapeutics, Cambridge, MA, USA. ${ }^{6}$ Indedpendent Medical Writer, San Diego, CA, USA. ${ }^{7}$ Institute of Psychiatry, Psychology and Neuroscience, King's College London, London, UK.

Received: 27 November 2017 Accepted: 13 June 2018

Published online: 25 June 2018

\section{References}

1. Swensen AR, Birnbaum HG, Secnik K, Marynchenko M, Greenberg P, Claxton A. Attention-deficit/hyperactivity disorder: increased costs for patients and their families. J Am Acad Child Adolesc Psychiatry. 2003;42(12):1415-23.

2. Chorozoglou M, Smith E, Koerting J, Thompson MJ, Sayal K, Sonuga-Barke EJ. Preschool hyperactivity is associated with long-term economic burden: evidence from a longitudinal health economic analysis of costs incurred across childhood, adolescence and young adulthood. J Child Psychol Psychiatry. 2015:56(9):966-75.

3. Diagnostic and statistical manual of mental disorders, 5th ed Washington, D.C.: American Psychiatric Association; 2013.

4. Polanczyk GV, Salum GA, Sugaya LS, Caye A, Rohde LA. Annual research review: a meta-analysis of the worldwide prevalence of mental disorders in children and adolescents. J Child Psychol Psychiatry. 2015;56(3):345-65.

5. Thomas R, Sanders S, Doust J, Beller E, Glasziou P. Prevalence of attentiondeficit/hyperactivity disorder: a systematic review and meta-analysis. Pediatrics. 2015;135(4):e994-1001. 
6. Moffitt TE, Houts R, Asherson P, Belsky DW, Corcoran DL, Hammerle M, Harrington $\mathrm{H}$, Hogan S, Meier MH, Polanczyk GV, et al. Is adult ADHD a childhood-onset neurodevelopmental disorder? Evidence from a fourdecade longitudinal cohort study. Am J Psychiatry. 2015;172(10):967-77.

7. Agnew-Blais JC, Polanczyk GV, Danese A, Wertz J, Moffitt TE, Arseneault L. Evaluation of the persistence, remission, and emergence of attentiondeficit/hyperactivity disorder in young adulthood. JAMA Psychiatry. 2016; 73(7):713-20.

8. Faraone SV, Biederman J, Mick E. The age-dependent decline of attention deficit hyperactivity disorder: a meta-analysis of follow-up studies. Psychol Med. 2006:36(2):159-65.

9. Polanczyk G, de Lima MS, Horta BL, Biederman J, Rohde LA. The worldwide prevalence of ADHD: a systematic review and metaregression analysis. Am J of Psychiatry. 2007;164(6):942-8

10. Simon V, Czobor P, Balint S, Meszaros A, Bitter I. Prevalence and correlates of adult attention-deficit hyperactivity disorder: meta-analysis. British J of Psychiatry. 2009;194(3):204-11.

11. Chang Z, Lichtenstein P, D'onofrio B, Sjölander A, Larsson H. Serious transport accidents in adults with attention-deficit/hyperactivity disorder and the effect of medication: a population-based study. JAMA Psychiatry. 2014;71(3):319-25.

12. Dalsgaard S, Ostergaard SD, Leckman JF, Mortensen PB, Pedersen MG. Mortality in children, adolescents, and adults with attention deficit hyperactivity disorder: a nationwide cohort study. Lancet. 2015;385(9983): 2190-6.

13. van Emmerik-van Oortmerssen $K$, van de Glind G, van den Brink W, Smit F, Crunelle $C L$, Swets $M$, Schoevers RA. Prevalence of attention-deficit hyperactivity disorder in substance use disorder patients: a metaanalysis and meta-regression analysis. Drug Alcohol Depend. 2012; 122(1-2):11-9.

14. Gudjonsson GH, Sigurdsson JF, Sigfusdottir ID, Asgeirsdottir BB, Gonzalez RA, Young S. A national epidemiological study investigating risk factors for police interrogation and false confession among juveniles and young persons. Soc Psychiatry Psychiatr Epidemiol. 2016;51(3):359-67.

15. Shaw M, Hodgkins P, Caci H, Young S, Kahle J, Woods AG, Arnold LE. A systematic review and analysis of long-term outcomes in attention deficit hyperactivity disorder: effects of treatment and non-treatment. BMC Med. 2012;10:99.

16. Danckaerts M, Sonuga-Barke EJ, Banaschewski T, Buitelaar J, Dopfner M, Hollis C, Santosh P, Rothenberger A, Sergeant J, Steinhausen HC, et al. The quality of life of children with attention deficit/hyperactivity disorder: a systematic review. Eur Child Adolesc Psychiatry. 2010;19(2):83-105.

17. Young S, Sedgwick O, Fridman M, Gudjonsson G, Hodgkins P, Lantigua M, Gonzalez RA. Co-morbid psychiatric disorders among incarcerated ADHD populations: a meta-analysis. Psychol Med. 2015;45(12):2499-510.

18. Gonzalez RA, Velez-Pastrana MC, Ruiz Varcarcel JJ, Levin FR, AlbizuGarcia CE. Childhood ADHD symptoms are associated with lifetime and current illicit substance-use disorders and in-site health risk behaviors in a representative sample of Latino prison inmates. J Atten Disord. 2015; 19(4):301-12.

19. Gudjonsson G, Sigurdsson JF, Young S, Newton AK, Peersen M. Attention deficit hyperactivity disorder (ADHD). How do ADHD symptoms relate to personality among prisoners? Personal Individ Differ. 2009;47:64-8.

20. Young S, Wells J, Gudjonsson GH. Predictors of offending among prisoners: the role of attention-deficit hyperactivity disorder and substance use. J Psychopharmacol. 2011;25(11):1524-32.

21. Gregory $G$, Reddy V, Young C. Identifying children who are at risk of FASD in Peterborough: working in a community clinic without access to gold standard diagnosis. Adoption Fostering. 2015;39(3):225-34.

22. Beecham J. Annual research review: child and adolescent mental health interventions: a review of progress in economic studies across different disorders. J Child Psychol Psychiatry. 2014;55(6):714-32.

23. Doshi JA, Hodgkins P, Kahle J, Sikirica V, Cangelosi MJ, Setyawan J, Erder MH, Neumann PJ. Economic impact of childhood and adult attentiondeficit/hyperactivity disorder in the United States. J Am Acad Child Adolesc Psychiatry. 2012;51(10):990-1002. e1002

24. Telford C, Green C, Logan S, Langley K, Thapar A, Ford T. Estimating the costs of ongoing care for adolescents with attention-deficit hyperactivity disorder. Soc Psychiatry Psychiatr Epidemiol. 2013;48(2):337-44.

25. Young S, Gonzalez RA, Mutch L, Mallet-Lambert I, O'Rourke L, Hickey N, Asherson P, Gudjonsson GH. Diagnostic accuracy of a brief screening tool for attention deficit hyperactivity disorder in UK prison inmates. Psychol Med. 2016;46:1449-58.

26. Horsman J, Furlong W, Feeny D, Torrance G. The health utilities index (HUI): concepts, measurement properties and applications. Health Qual Life Outcomes. 2003;1:54.

27. Health Utilities Inc. http://www.healthutilities.com/. Accessed 29 Oct 2017.

28. Patrick DL, Erickson P. Health Status and Health policy: quality of life in health care evaluation and resource allocation. NewYork: Oxford University Press; 1993.

29. Sikirica V, Pliszka SR, Betts KA, Hodgkins P, Samuelson T, Xie J, Erder H, Dammerman R, Robertson B, Wu EQ. Comparative treatment patterns, resource utilization, and costs in stimulant-treated children with ADHD who require subsequent pharmacotherapy with atypical antipsychotics versus non-antipsychotics. J Manag Care Pharm. 2012;18(9):676-89.

30. Kooij JJS. Diagnostic Interview for ADHD in Adults 2.0 (DIVA 2.0). In: Adult ADHD: Diagnostic assessment and treatment. Amsterdam, ND: Pearson Assessment and Information BV; 2010.

31. Deberdt W, Thome J, Lebrec J, Kraemer S, Fregenal I, Ramos-Quiroga JA, Arif M. Prevalence of ADHD in nonpsychotic adult psychiatric care (ADPSYC): a multinational cross-sectional study in Europe. BMC Psychiatry. 2015;15(1):242.

32. Young S, Goodwin EJ, Sedgwick O, Gudjonsson GH. The effectiveness of police custody assessments in identifying suspects with intellectual disabilities and attention deficit hyperactivity disorder. BMC Med. 2013;11:248.

33. Derogatis LR. The Brief Symptom Inventory: Administration, Scoring, and Procedures Manual. 4th ed. Minneapolis, MN: National Computer Systems; 1993.

34. Personal Social Services Research Unit. Unit Costs of Health and Social Care. 2014. http://www.pssru.ac.uk/project-pages/unit-costs/2014/. Accessed 29 Oct 2017

35. HM Prison Service. Prison population figures. Ministry of Justice. 2016. https://www.gov.uk/government/statistics/prison-population-figures-2016. Accessed 29 Oct 2017

36. The Social Research Unit at Dartington. Investing in Children: Technical Report. Dartington: Dartington Press; 2013.

37. UCLA Statistical Consulting Group. Introduction to SAS. 2007. http://www. ats.ucla.edu/stat/sas/notes2. Accessed 28 Apr 2016.

38. Wedderburn RWM. Quasi-likelihood functions, generalized linear models, and the gauss Newton method. Biometrika. 1974;61:439-47.

39. StataCorp. Stata Statistical Software: Release 13. College Station, TX: StataCorp LP; 2013.

40. Naeim A, Keeler EB, Mangione CM. Options for handling missing data in the health utilities index mark 3. Med Decis Mak. 2005;25(2):186-98.

41. Riley AW, Spiel G, Coghill D, Dopfner M, Falissard B, Lorenzo MJ, Preuss U, Ralston SJ, Group AS. Factors related to health-related quality of life (HRQoL) among children with ADHD in Europe at entry into treatment. Eur Child Adolesc Psychiatry. 2006;15(Suppl 1):138-45.

42. Coghill $D$, Hodgkins $P$. Health-related quality of life of children with attention-deficit/hyperactivity disorder versus children with diabetes and healthy controls. Eur Child Adolesc Psychiatry. 2015;25(3):261-71.

43. Young S, Gudjonsson GH, Wells J, Asherson P, Theobald D, Oliver B, Scott C, Mooney A. Attention deficit hyperactivity disorder and critical incidents in a Scottish prison population. Personal Individ Differ. 2009;46:265-9.

44. Peasgood T, Bhardwaj A, Biggs K, Brazier JE, Coghill D, Cooper CL, Daley D, De Silva C, Harpin V, Hodgkins $P$, et al. The impact of ADHD on the health and well-being of ADHD children and their siblings. Eur Child AdolesC Psychiatry. 2016:25(11):1217-31.

45. Erskine HE, Ferrari AJ, Polanczyk GV, Moffitt TE, Murray CJ, Vos T, Whiteford HA, Scott JG. The global burden of conduct disorder and attention-deficit/ hyperactivity disorder in 2010. J Child Psychol Psychiatry. 2014;55(4):328-36.

46. Limbers CA, Ripperger-Suhler J, Boutton K, Ransom D, Varni JW. A comparative analysis of health-related quality of life and family impact between children with ADHD treated in a general pediatric clinic and a psychiatric clinic utilizing the PedsQL. J Atten Disord. 2011;15(5):392-402.

47. Lee YC, Yang HJ, Chen VC, Lee WT, Teng MJ, Lin CH, Gossop M. Metaanalysis of quality of life in children and adolescents with ADHD: by both parent proxy-report and child self-report using PedsQL. Res Dev Disabil. 2016:51-52:160-72.

48. Klassen AF, Miller A, Fine S. Health-related quality of life in children and adolescents who have a diagnosis of attention-deficit/hyperactivity disorder. Pediatrics. 2004;114(5):e541-7.

49. Herringa RJ, Birn RM, Ruttle PL, Burghy CA, Stodola DE, Davidson RJ, Essex MJ. Childhood maltreatment is associated with altered fear circuitry and 
increased internalizing symptoms by late adolescence. Proc Natl Acad Sci U S A. 2013;110(47):19119-24.

50. Hakkaart-van Roijen L, Zwirs BW, Bouwmans C, Tan SS, Schulpen TW, Vlasveld L, Buitelaar JK. Societal costs and quality of life of children suffering from attention deficient hyperactivity disorder (ADHD). Eur Child Adolesc Psychiatry. 2007;16(5):316-26.

51. Jones DE, Foster EM. Conduct problems prevention research G.: service use patterns for adolescents with ADHD and comorbid conduct disorder. J Behav Health Serv Res. 2009;36(4):436-49.

52. Leibson CL, Katusic SK, Barbaresi WJ, Ransom J, O'Brien PC. Use and costs of medical care for children and adolescents with and without attentiondeficit/hyperactivity disorder. JAMA. 2001;285(1):60-6.

53. Wu EQ, Birnbaum HG, Zhang HF, Ivanova Jl, Yang E, Mallet D. Health care costs of adults treated for attention-deficit/hyperactivity disorder who received alternative drug therapies. J Manag Care Pharm. 2007:13(7):561-9.

54. Gordon V, Williams DJ, Donnelly PD. Exploring the relationship between ADHD symptoms and prison breaches of discipline amongst youths in four Scottish prisons. Public Health. 2012;126(4):343-8.

55. Young S, Moss D, Sedgwick O, Fridman M, Hodgkins P. A meta-analysis of the prevalence of attention deficit hyperactivity disorder in incarcerated populations. Psychol Med. 2015;45(2):247-58.

56. Young SJ, Adamou M, Bolea B, Gudjonsson G, Muller U, Pitts M, Thome J, Asherson P. The identification and management of ADHD offenders within the criminal justice system: a consensus statement from the UK adult ADHD network and criminal justice agencies. BMC Psychiatry. 2011;11:32.

57. Lichtenstein P, Halldner L, Zetterqvist J, Sjolander A, Serlachius E, Fazel S, Langstrom N, Larsson H. Medication for attention deficit-hyperactivity disorder and criminality. N Engl J Med. 2012;367(21):2006-14.

Ready to submit your research? Choose BMC and benefit from:

- fast, convenient online submission

- thorough peer review by experienced researchers in your field

- rapid publication on acceptance

- support for research data, including large and complex data types

- gold Open Access which fosters wider collaboration and increased citations

- maximum visibility for your research: over $100 \mathrm{M}$ website views per year

At BMC, research is always in progress.

Learn more biomedcentral.com/submissions 